\title{
HPV16 \\ AND CANCER PREVENTION
}

\author{
PROFESSOR AMBER D'SOUZA, BASED AT JOHNS HOPKINS \\ BLOOMBERG SCHOOL OF PUBLIC HEALTH IN THE US, IS \\ WORKING TO DEVELOP IMPROVED MEANS OF DETECTING \\ ORAL HPV16 INFECTION. THE FINDINGS COULD HELP \\ DETECT OROPHARYNGEAL CANCERS CAUSED BY HPV \\ EARLIER AND REDUCE CANCER INCIDENCE
}

\section{TALK LIKE AN HPV RESEARGHER}

HUMAN PAPILLOMAVIRUS (HPV)

the most common viral infection of the reproductive tract

OROPHARYNX - the middle part of the pharynx (throat and back of the mouth)

OROPHARYNGEAL CANCER - a type of head and neck cancer

\section{SEXUALLY TRANSMITTED}

INFECTION - infections that usually pass from one person to another through sexual contact

HPV-OPC - a cancer of the throat caused by the human papillomavirus

HPV16 - human papillomavirus type 16

CANCER PREVENTION - action taken to lower the risk of getting cancer
The human papillomavirus (HPV) is the most common sexually transmitted infection in the world, with approximately 43 million HPV infections in 2018. In most instances, HPV is combatted by the body's immune system and does not cause any health issues or problems. However, sometimes the infection persists and leads to problems such as genital warts and cancer. In addition to causing oropharyngeal cancer, HPV can cause cervical, anal, penile and vaginal cancer. There are many different HPV strains that can cause cancer, but one type, HPV16, causes most HPV-related cancers.

Around $1 \%$ of men and $0.5 \%$ of women in the general US population have an oral HPV16 infection, with $10-20 \%$ of men and $4-10 \%$ of women having an oral HPV16 infection at some time in their life. Most people clear these infections on their own - through their immune systems - but, in some people, these infections persist and, after many years, progress to cause oropharyngeal cancer (or another form of cancer).

Indeed, HPV causes most oropharyngeal cancers in the US - this form of the cancer is called HPV-OPC. However, there are still no effective screening methods to detect these cancers. It is with this in mind that Professor Amber D'Souza, based at Johns Hopkins Bloomberg School of Public Health, and her colleagues, established

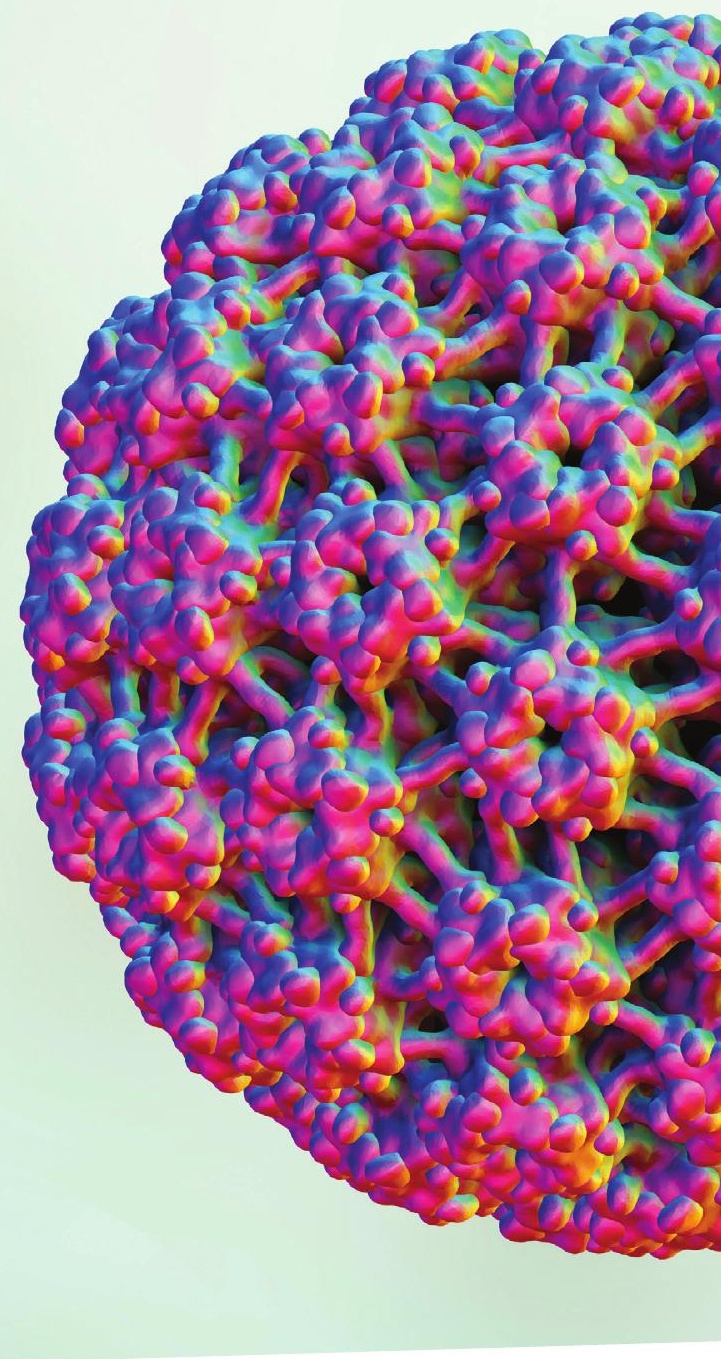

a project that seeks to improve the prevention and screening of these cancers, with a view to improving patient outcomes.

\section{IF SOMEONE HAS HAD THE HPV}

VACCINE, TO WHAT EXTENT ARE THEY PROTECTED FROM HPV-OPC?

The HPV vaccine is very good at preventing new HPV infections, so among vaccinated individuals the risk of oral HPV infection is very low. "The HPV vaccine programme began in 2006 and targets young people because the HPV vaccine doesn't help clear an HPV infection a person already has when they are vaccinated and so doesn't work as well among older individuals," explains Amber. "By 2045, the rate of oropharyngeal cancer among young people ( $<45$ years old) will have halved because of $H P V$ vaccination that is happening now. Because most oropharyngeal cancer occurs in older people - people who have not been vaccinated -, it will take several decades before the overall rate of oropharyngeal cancer decreases."

\section{WHAT TREATMENT IS CURRENTLY} AVAILABLE FOR HPV-OPC PATIENTS?

There are several means of treating HPVOPC patients, including surgery, radiation chemotherapy or a combination of the two. Many patients recover completely after treatment, without any serious side effects. However, for 


\section{. ABOUT EPIDEMIOLOGY}

Epidemiology is the study of disease or injury patterns in human populations. Initially, Amber wanted to study environmental science or wildlife biology, but came to realise that helping humans was her main interest. Amber knew she wanted to be an epidemiologist when she saw the impact it can have on public health. Epidemiologists are an important part of preventive health care systems

- Amber has shown in her research how important epidemiology is in preventing and treating infections.

Amber's work has also seen her researching other infections like HIV and coronavirus, so there is a need for her to switch between research areas and compartmentalise the different projects. "I like to work on questions where there are still lots of unknowns to answer - finding those answers is an exciting feeling. I do work across different topic areas, following interesting or pressing scientific questions in whatever area they arise," explains Amber. "My training was in infectious disease, and because I studied HPV (which can cause cancer), it led me to also become an expert in cancer, and I now feel at home in both research areas."
HOW HAS AMBER DEVELOPED

THE COMMUNICATION SKILLS

NECESSARY TO DISSEMINATE

HER RESEARCH?

Amber's work, particularly regarding

COVID-19, necessitates doing interviews with the press, which has been a big learning curve for her. As the pandemic worsened, Amber conducted interviews with the press multiple times per week in 2020 and 2021, which naturally made her better - practice makes perfect! "The parts of my work I most enjoy are exploring the data to find answers in our research studies to questions we had, and then being able to communicate that information to the people who have questions about that disease or infection," she says. "I enjoy the press interviews because I know it helps communicate what we know to the public, which is important to me."

WHAT MOTIVATES AMBER TO DO THE WORK SHE DOES?

Amber went into public health to try and make a difference to people's lives. "I really believe in the power of prevention and using our health tools to decrease suffering and save lives, such as risk-reduction through changing our behaviour to reduce infections like HPV, HIV, or coronavirus from spreading, and promoting vaccination," she explains. "I am motivated to help people who have a disease, whether that is by improving screening to detect it early or helping to understand the course of the disease."

WHAT ISSUES WILL THE NEXT GENERATION OF EPIDEMIOLOGISTS FACE?

Epidemiology is a science that is largely about how to correctly design, conduct and analyse research studies. As many of the more direct exposure-disease links have been worked out, the questions being asked are about increasing complex relationships where many factors interact. If you want to help humans and advance our understanding of diseases, then epidemiology might be the perfect career!

\section{PATHWAY FROM SCHOOL TO EPIDEMIOLOGY}

Some colleges and universities have public health programmes, so Amber suggests researching particular institutions. As for subjects, she says, "Classes in science, especially biology and mathematics (in topics such as statistics), are useful. Programming skills also help as we do a lot of data management and analysis in epidemiology."

- ExploreHealthCareers.org provides a lot of useful information, particularly for those based in the US who are interested in epidemiology.

- According to Salary.com, salaries for epidemiologists in the US (depending on experience and role) range between $\$ 73,000$ and $\$ 138,000$ (and more when you have a PhD): www.salary.com/research/salary/benchmark/epidemiologist-salary

- The American Public Health Association has general information about public health, which is a good place to start. Some health departments have part-time jobs or volunteer opportunities that can be a great introduction to public health and epidemiology. www.apha.org

\section{$18+1$}

\section{AMBER'S TOP TIP}

Find something you enjoy doing! It took me a while to find epidemiology; I worked in lab science and as a teacher before working for the health department where I found out how

much I enjoyed public health. For my master's, I took classes in different fields of public health. I had never heard of epidemiology, but when I took those courses, I knew I had found something I really loved and was good at! 
